\title{
Construction of Indoor Spatial Information using Indoor Mobile Mapping System
}

\author{
Joon-Kyu Park ${ }^{1}$ and Kap-Yong Jung ${ }^{2 *}$ \\ ${ }^{1}$ Department of Civil Engneering, Seoil University, \\ 28, Yongmasan-ro 90-gil, Jungnang-gu, Seoul, Korea \\ ${ }^{2}$ Department of Civil Engneering, Graduate School, Chungnam National \\ University, 99 Daehak-ro, Yuseong-gu, Daejeon, South Korea \\ 1'jkpark@seoil.ac.kr, ${ }^{2}$ jungjusa@hanmail.net
}

\begin{abstract}
As mobile devices and surveying techniques have developed and special information market has expanded in recent years, a scope that spatial information technique which was limited to outdoor space is expanding into indoor space. Information on indoor space can be served in various fields. Information on indoor space can be used in providing welfare and administration services. Conducting construction work effectively based on information on indoor space may lead to creation new industrial fields. However, research on a new method for construction of indoor spatial information is lacking. This study has built information on indoor space the study participants by using Indoor Mobile Mapping System which various sensors such as IMU(Inertial Measurement Unit), camera, $3 D$ laser scanner, DMI(Distance Measurement Instrument) are combined. The method devised by this study can establish information on indoor space of targeted regions more efficiently than existing methods which used total station or $3 D$ laser scanner. Established information on indoor space is related to 360 degree panorama image and point cloud and its accuracy were evaluated. Modeling the target was conducted effectively by using point cloud. It took 50 minutes to acquire information on 9 indoor spaces which lay in area of about $50 \mathrm{~m} \times 30 \mathrm{~m}$ which was significantly shorter than time which took by using laser scanner only. It is expected that the bigger indoor space is, the higher such difference is. Indoor MMS(Mobile Mapping System) is expected to make a great contribution to improving productivity of establishing information on indoor space.
\end{abstract}

Keywords: Indoor Spatial Information; Mobile Mapping System; Availability Evaluation; 3D Modeling; 3D Laser Scanner

\section{Introduction}

Spatial information is closely related to everyday life of people beyond simple delivery of position information. Spatial information is considered to be essential in everyday life[1-2]. Spatial information technology has developed into technology that changes personal lifestyle beyond provision of various information[3-5]. In these days buildings have become large by development of construction technology and increase in population density in metropolitan cities, indoor space in which people spend over $80 \%$ of their time has been considered important[6-10]. Thus, scope of spatial information service has expanded into indoor space as well as outdoor space rapidly. It is expected that such change will create various service demand such as portal of information on indoor space, support for a person who is visually impaired, disaster response, subway use, indoor security making good use of development of high-technology for example IT and mobile

Received (June 22, 2018), Review Result (August 10, 2018), Accepted (August 16, 2018)

* Corresponding Author 
devices[11-14]. Subway fire in Daegu which broke out in 2003 claimed 192 lives and injured 138 people[15-16]. At that time the accident broke out, information on the inside of Daegu subway station was not secured which caused massive causalities. Since then, Korean Government has established system to cope with various disasters that break out in public facilities making good use of information on indoor space[17-18]. In recent years, scope of special information service has expanded into indoor space as well as outdoor space rapidly and it is expected that such change will create various service demand making good use of development of high-technology for example IT and mobile devices[19-22]. However, research on a new method for construction of indoor spatial information is lacking. The purpose of this study is to establish information on indoor space in targets by using Indoor Mobile Mapping System in which various sensors such as IMU, camera, 3D laser scanner, DMI are combined and to evaluate its utilization. Figure 1 shows study flow.

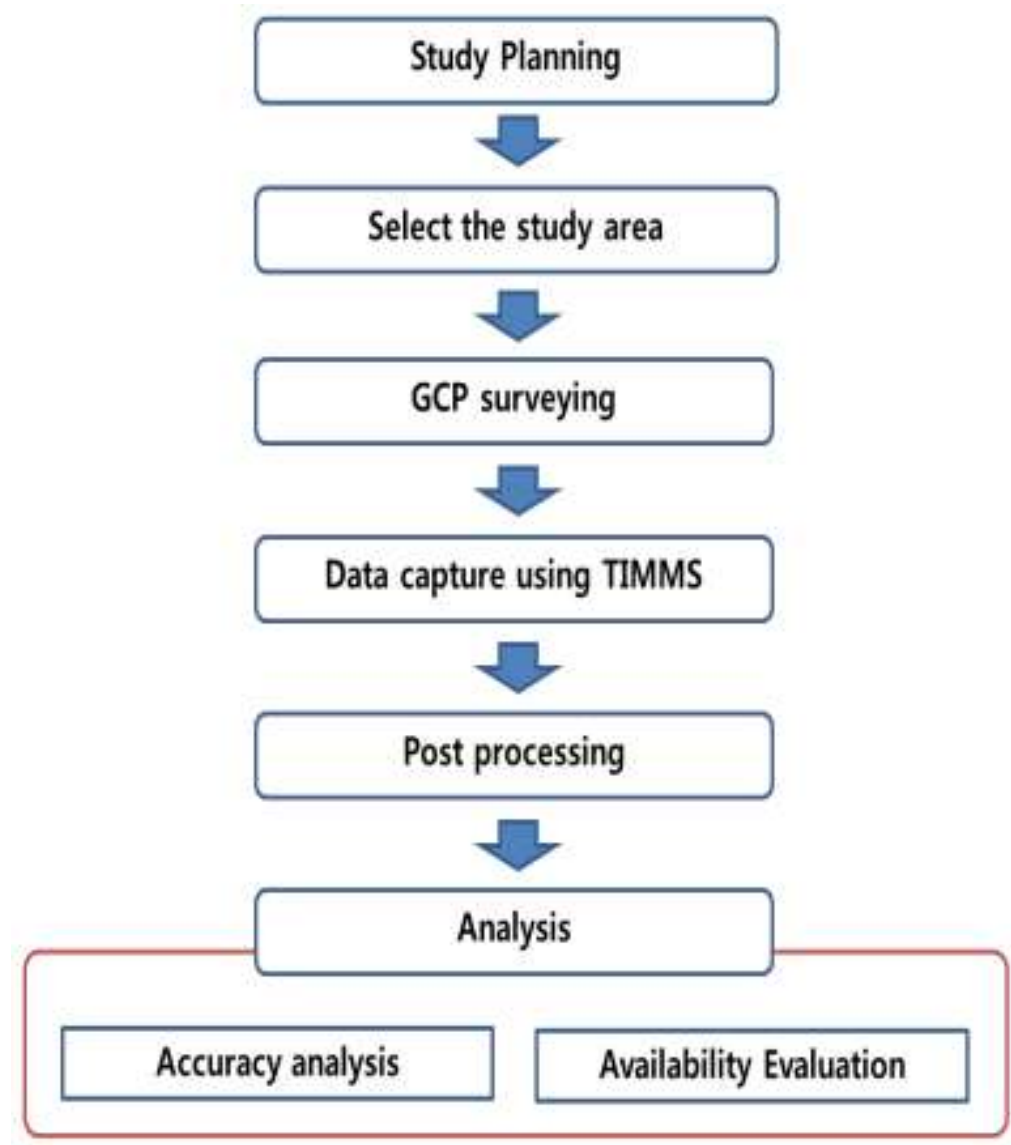

Figure 1. Study Flow

\section{Study Area and Acquisition of Spatial Information}

A building which was under construction and located in Incheon was selected in order to establish information on indoor space. The building was selected for this study because it did not have any things such as furniture that may obstruct acquisition of information on indoor space. Figure 2 shows the building selected for this study. 

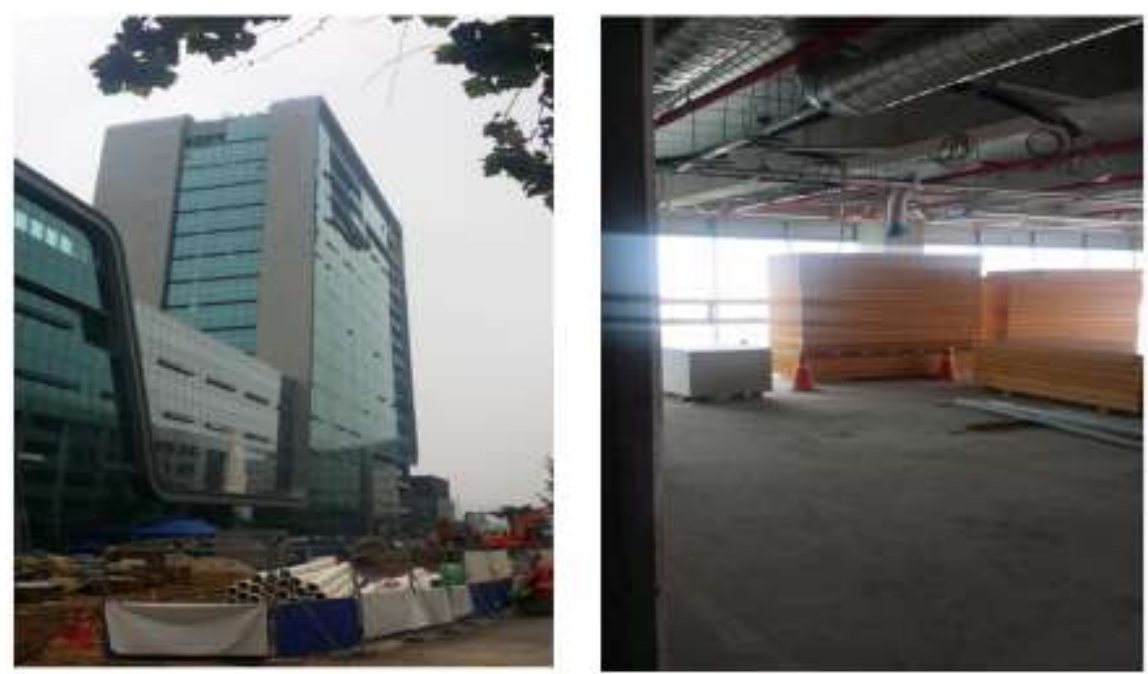

Figure 2. Study Area

TIMMS(Trimble Indoor Mobile Mapping Solution) was used to acquire data in this study. TIMMS was developed to acquire information on indoor space with MMS in which various sensors such as IMU, DMI, 3D laser scanner and camera are combined.

The greatest difference between TIMMS and MMS which is based on vehicle that is used in outdoors is that there is no GNSS(Global Navigation Satellite System). It is difficult to receive satellite signal indoor. Positioning is performed by using highly efficient IMU and DMI.

TIMMS is the optimal fusion of technologies for capturing spatial data of indoor and other GNSS does not matter areas of all sizes and locations. It provides both LiDAR and spherical video of a facility, enabling the creation of accurate, real-life representations of interior spaces and all of its contents. Figure 3 shows TIMMS[23].

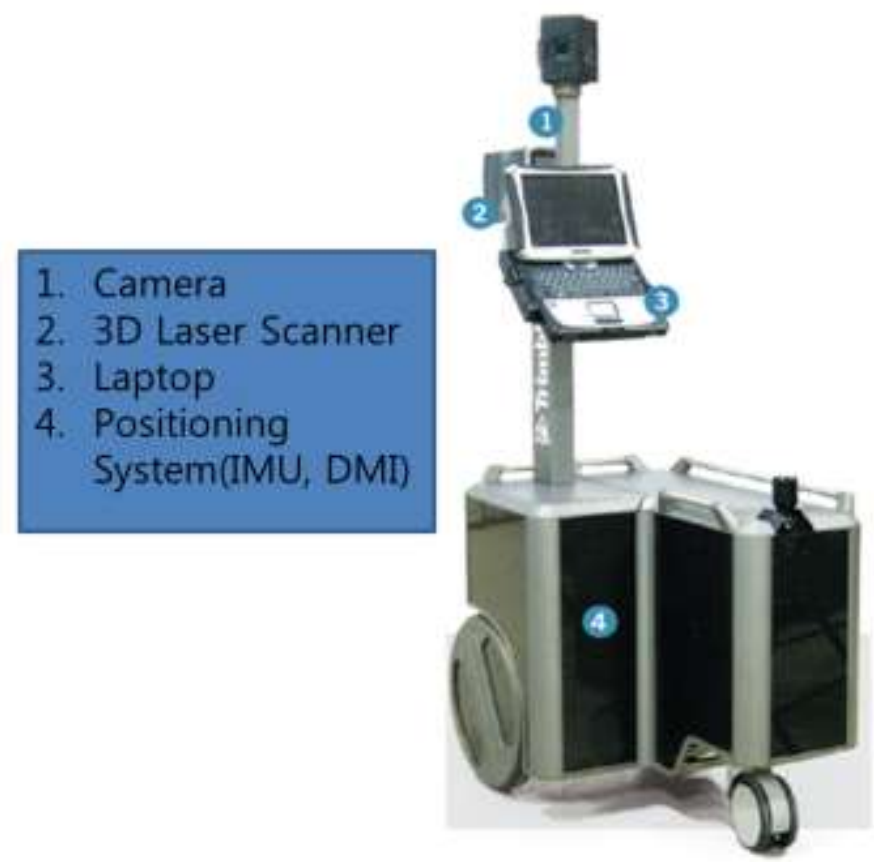

Figure 3. TIMMS 
This study set up five GCPs(Ground Control Point) and three check points to establish information on indoor space. GCPs were used to initialize TIMMS and correct position. Check point was used to evaluate accuracy of established spatial information. Table 1 shows coordinate of GCP and check point.

Table 1. Coordinate of GCP and Check Point

\begin{tabular}{|c|c|c|c|}
\hline Point & $\mathrm{X}(\mathrm{m})$ & $\mathrm{Y}(\mathrm{m})$ & $\mathrm{H}(\mathrm{m})$ \\
\hline GCP1 & 4147408.443 & 292476.584 & 58.343 \\
\hline GCP2 & 4147424.746 & 282485.990 & 58.345 \\
\hline GCP3 & 4147434.857 & 292491.633 & 58.368 \\
\hline GCP4 & 4147444.184 & 292496.884 & 58.355 \\
\hline GCP5 & 4147458.527 & 292505.193 & 58.349 \\
\hline Check1 & 4147425.451 & 292492.025 & 60.174 \\
\hline Check2 & 4147436.973 & 292486.068 & 29.945 \\
\hline Check3 & 4147451.708 & 292496.884 & 60.224 \\
\hline
\end{tabular}

Spatial information was acquired by initializing TIMMS in GCP 1. GCPs 2 5 were used to correct a position while acquiring data. Spatial information was acquired by using 360 degree panorama camera 3D laser scanner. Spatial information was synchronized with path information which was acquired in IMU and DMI. Data acquisition was conducted for 9 indoor spaces which lay in area of about $50 \mathrm{~m} \times 30 \mathrm{~m}$. Figure 4 shows a scene that data are acquired.

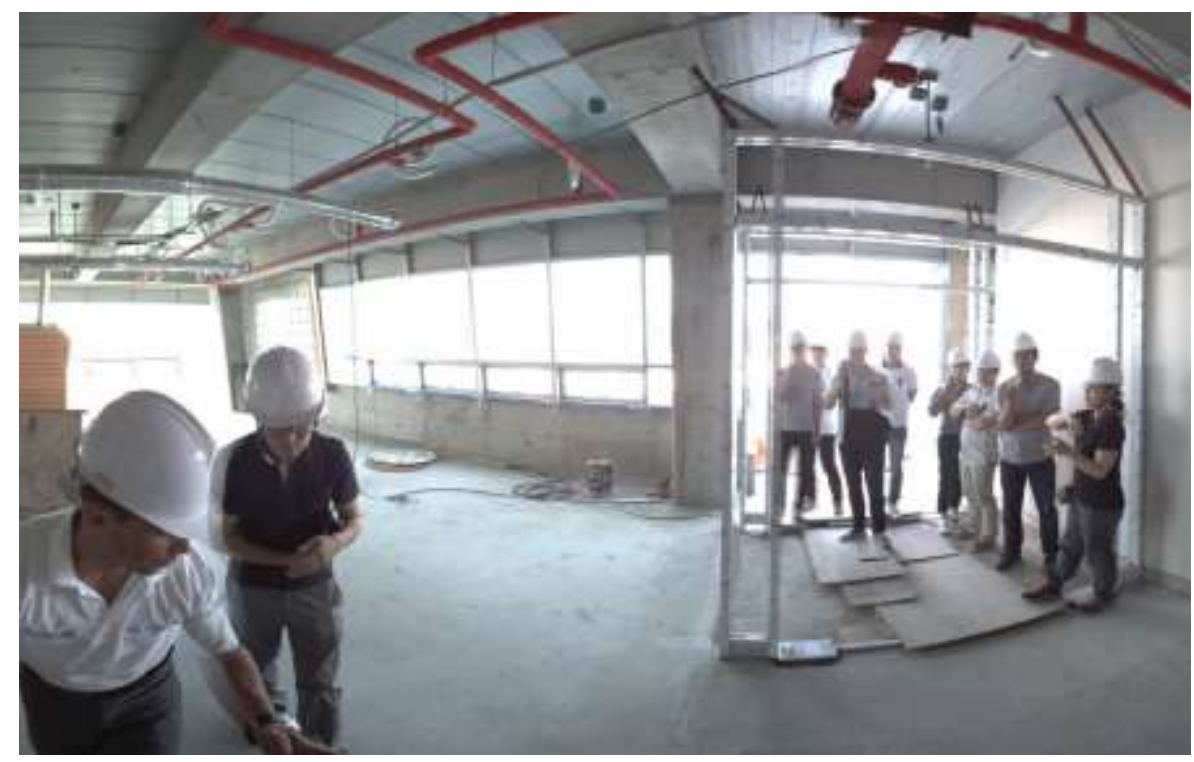

Figure 4. Data Capturing

Data acquired in TIMMS is post processed by using POSPac software. Post processing is conducted in order of import of IMU and DMI data, input of GCPs, creation of path information, creation of point cloud and creation of panorama image. Figure 5 shows post processing screen. 


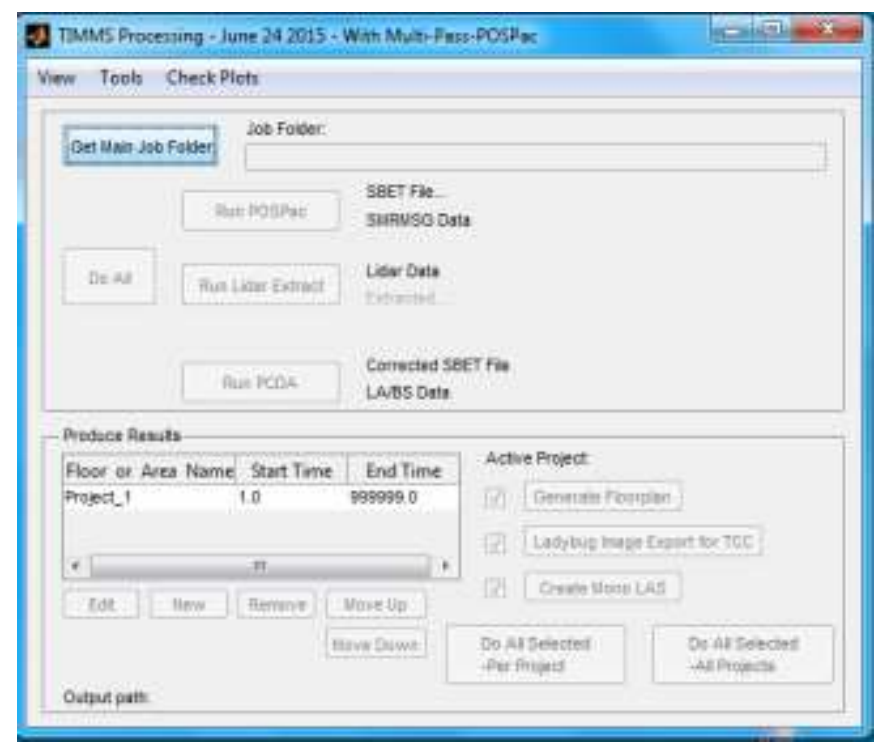

Figure 5. Post Processing Screen

Post processed data are created to las format point cloud and jpg format panorama images. Figure 6 shows point cloud. Figure 7 shows panorama image.

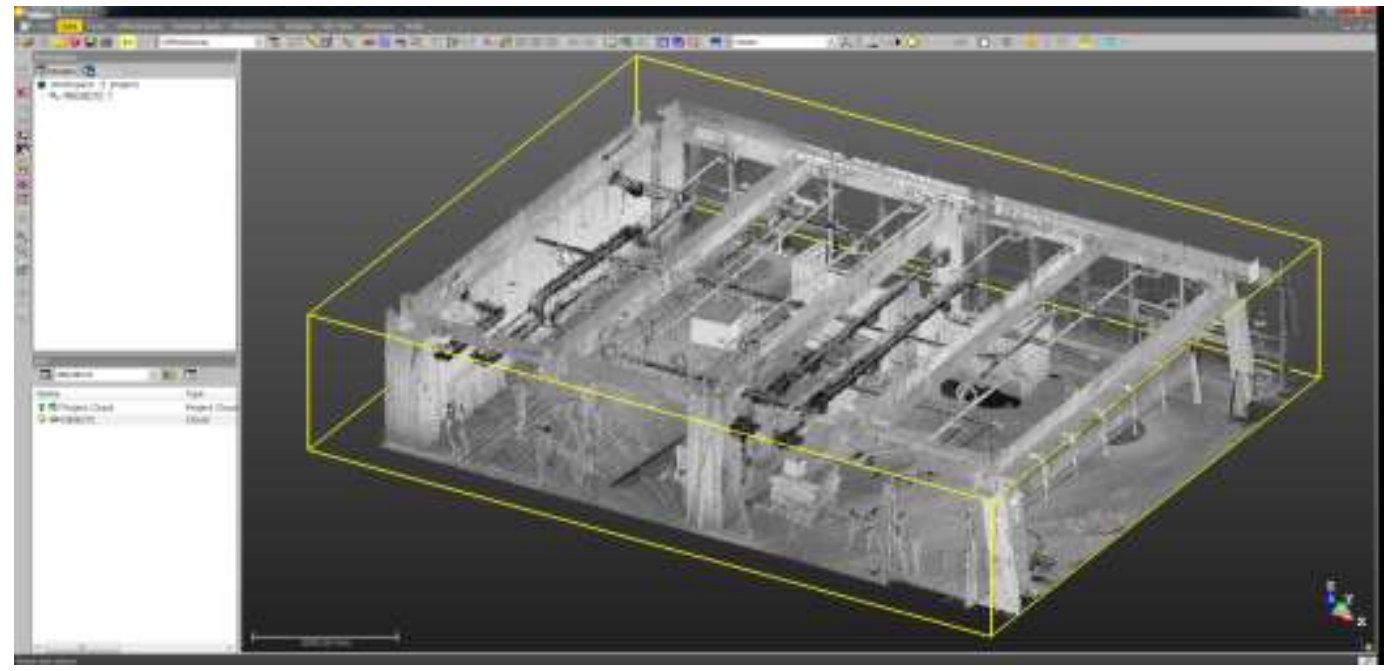

Figure 6. Point Cloud

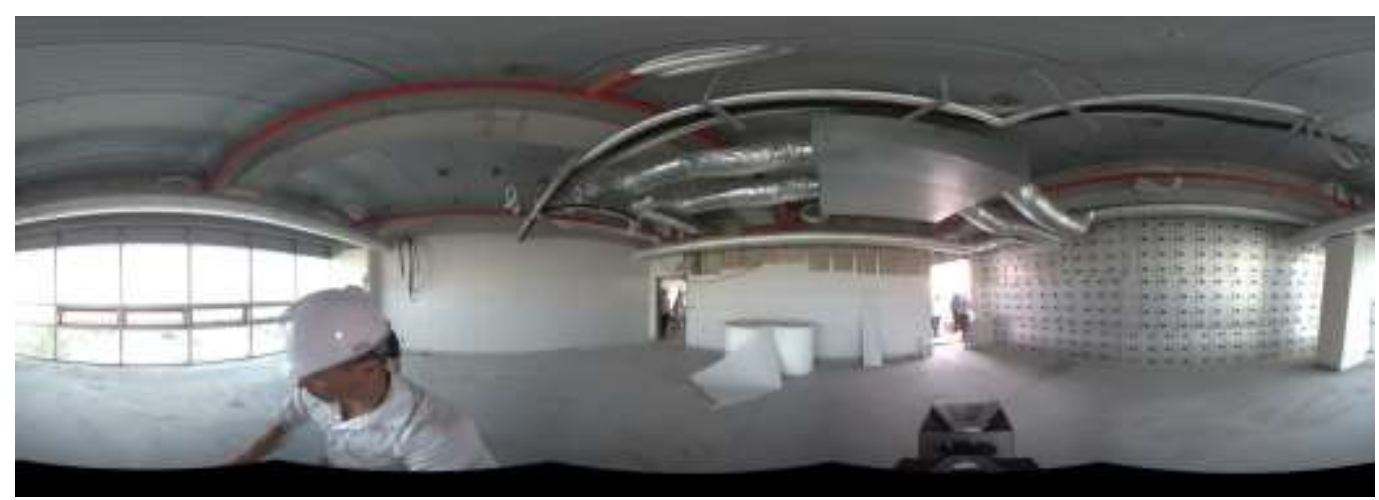

Figure 7. Panorama Image 


\section{Data Processing}

This study evaluated utilization of information on indoor space which was acquired by using TIMMS. Accuracy was analyzed to evaluate utilization of information on indoor space which was acquired by using TIMMS. Modeling and creation of sectional view of the building were conducted by using acquired spatial information.

Coordinates of check points in data which were acquired from TIMMS were obtained and they were compared with coordinates which were surveyed with total station to evaluate accuracy. Table 2 shows a result of accuracy evaluation.

Table 2. Result of Accuracy Evaluation

\begin{tabular}{|c|c|c|c|}
\hline Point & $\mathrm{dX}(\mathrm{m})$ & $\mathrm{dY}(\mathrm{m})$ & $\mathrm{dH}(\mathrm{m})$ \\
\hline Check1 & 0.014 & 0.009 & 0.018 \\
\hline Check2 & 0.007 & 0.008 & 0.012 \\
\hline Check3 & 0.019 & 0.013 & 0.015 \\
\hline
\end{tabular}

A difference between coordinates which were acquired with TIMMS and total station was found to be no more than $2 \mathrm{~cm}$. Spatial information on the building of this study was acquired by using existing method and a method which was devised in this study and time that it took when using the methods was compared. Only 3D laser scanner was used in acquiring data and the other conditions in the methods were same. Scanner was installed eleven times to acquire data. Sphere target was installed for registration. It took 3 hours to work in total. When using TIMMS, it took 45 minutes which included 30 minutes that was required for initialization to acquire data. The larger area of the building, the more difference in time that takes to acquire information is. Such result shows efficiency of TIMMS. Acquired point cloud and panorama image can be used in producing data with high utilization. This study created a floor plan of the building by using point cloud. Figure 8 shows a floor plan.

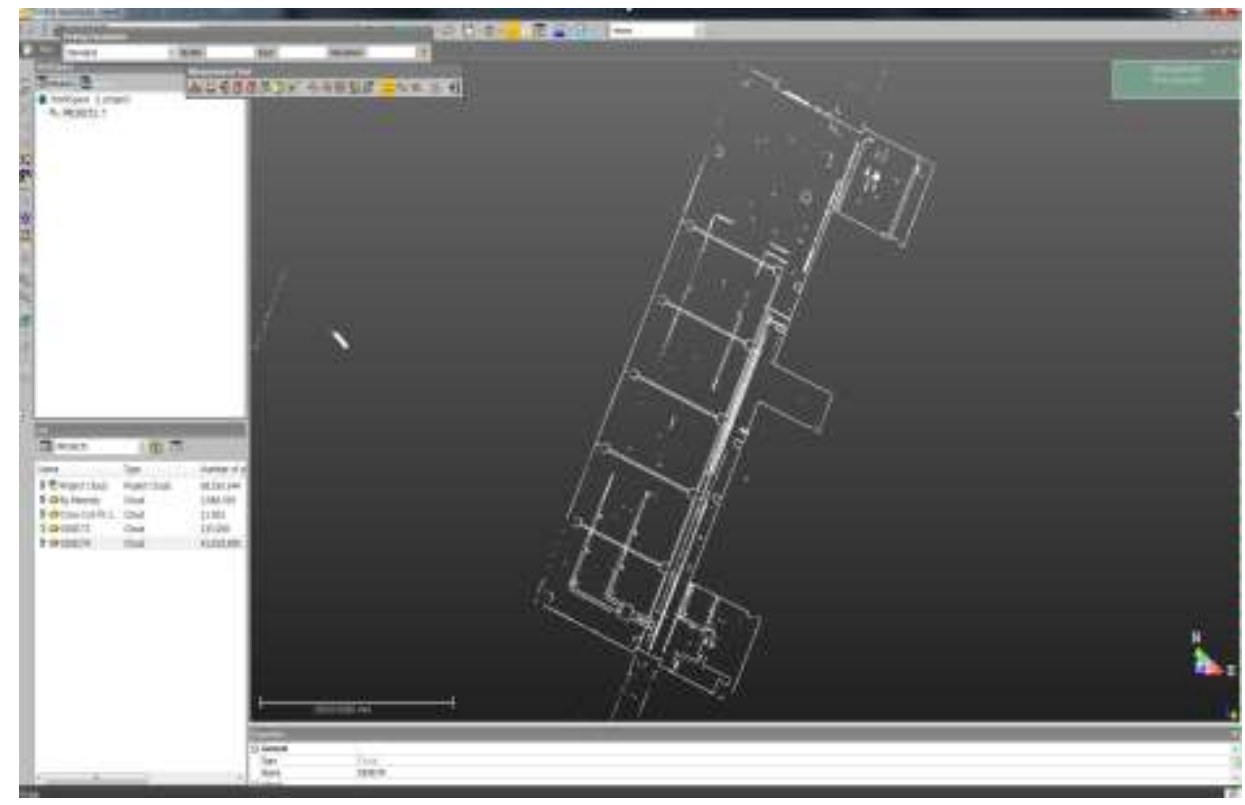

Figure 8. Floor Plan

A floor plan was created by using sectional view in point cloud easily. Data such as sectional view can be used widely in construction and civil engineering. This study 
conducted modeling of indoor space by using Realworks software. Modeling was conducted for some of 9 indoor spaces. Figure 9 shows modeling process and Figure 10 shows modeling result.

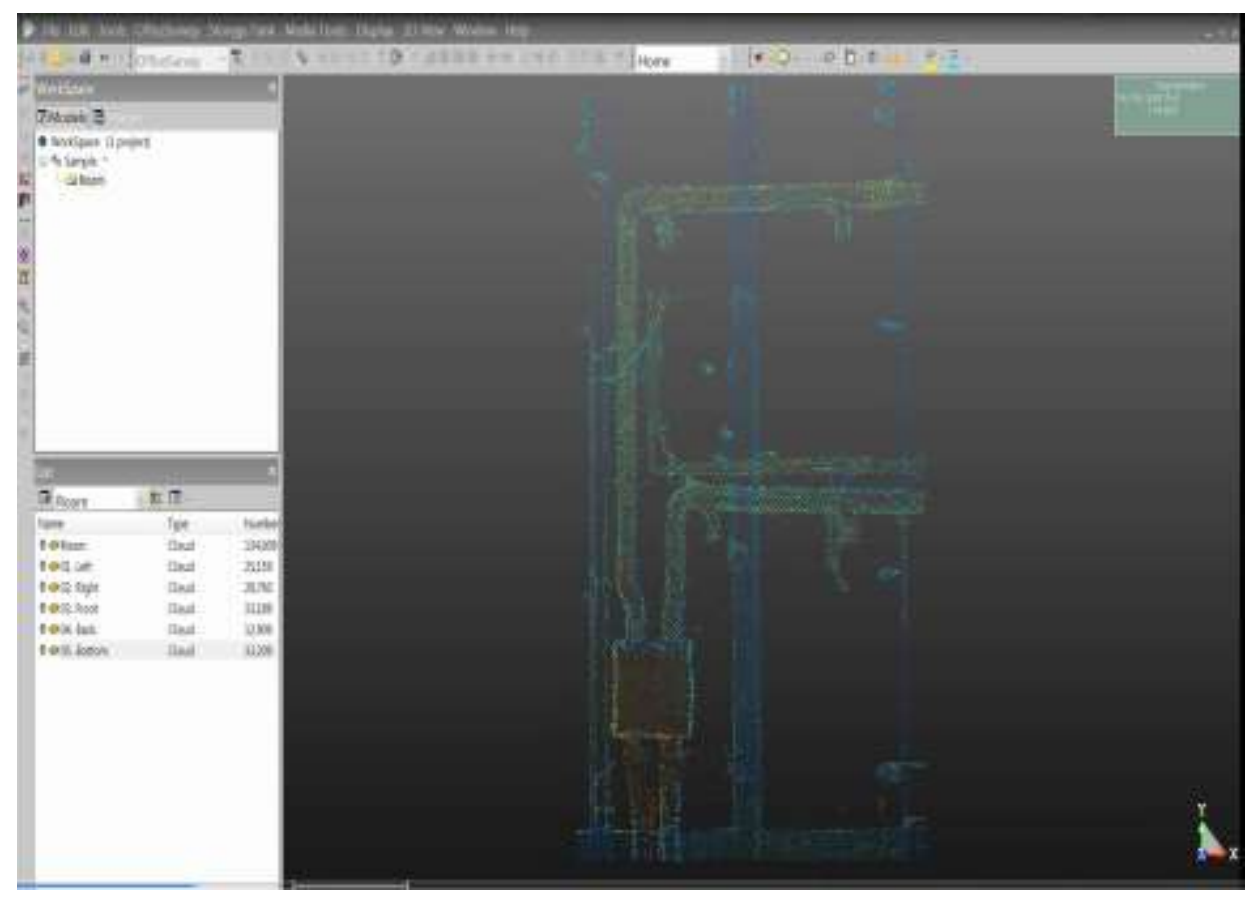

Figure 9. Modeling Process

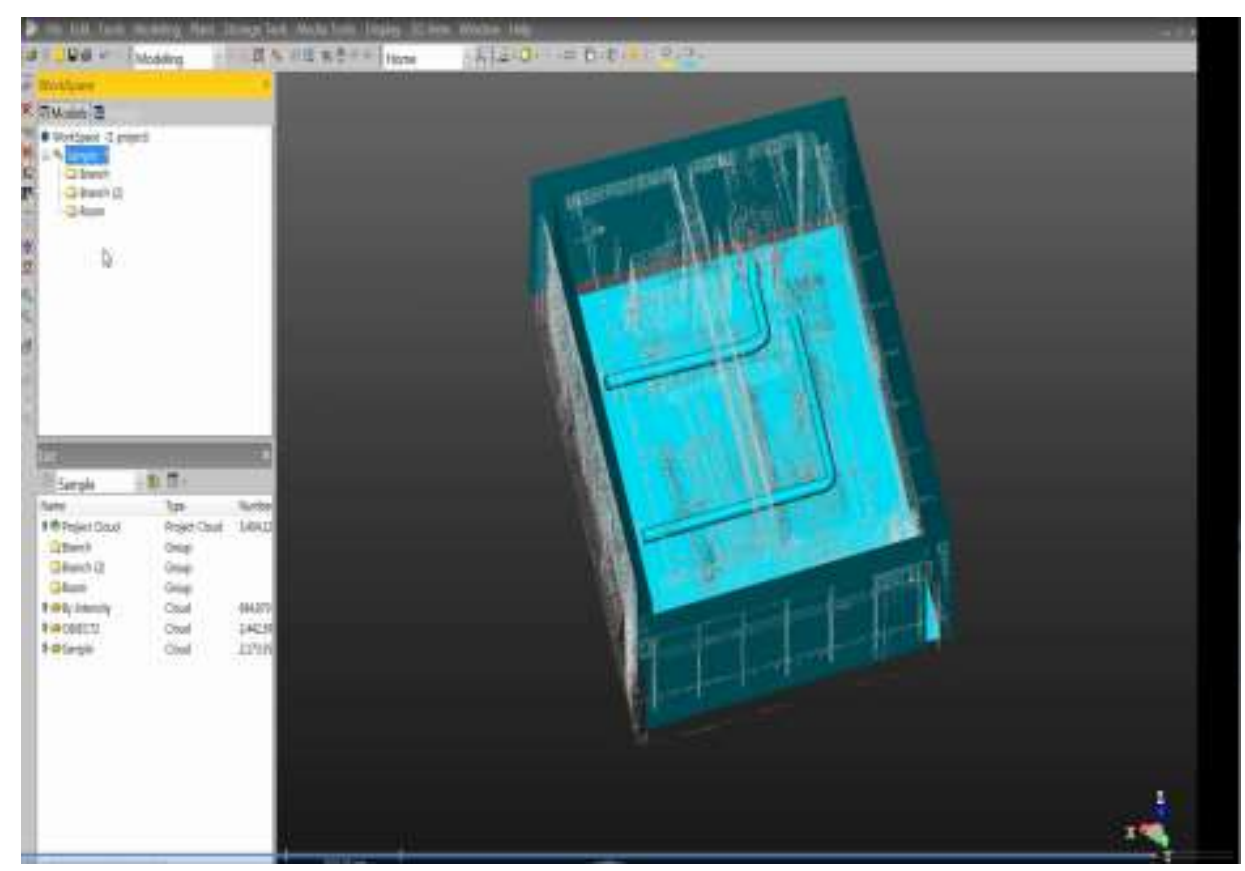

Figure 10. Modeling Result

In recent days, reverse engineering of indoor space that does not have drawings has drawn attention. Modeling data which use data acquired with TIMMS can be used in BIM related field. As there is no definition on accuracy and rules on establishing information on indoor space by law, it is difficult to judge with proper criteria but it is expected that accuracy of TIMMS will be used in establishing information on indoor space. It is 
expected that a method devised in this study will shorten time that it takes to establish spatial information significantly.

\section{Conclusions}

This study established information on indoor space of the building by using Indoor Mobile Mapping System in which various sensors such as IMU, camera, 3D laser scanner, DMI were combined and evaluated utilization of the information. Findings of this study are as follows.

Spatial information on 9 indoor spaces which lay in area of about $50 \mathrm{~m} \times 30 \mathrm{~m}$ was established. Accuracy of established data was found to be no more than $2 \mathrm{~cm}$. Time which takes to establish information when using TIMMS is significantly shorter than that when using Total Station or 3D laser scanner. Using point cloud helps conduct modeling of the building efficiently. As far as accuracy is concerned, now that there is no definition on accuracy and rules on establishing information on indoor space by law, it is difficult to judge with proper criteria but it is expected that accuracy of TIMMS will be used in establishing information on indoor space. As far as efficiency of establishment of spatial information, it is expected that a method devised in this study will shorten time that takes to establish information significantly. If relevant laws and rules are established and equipment which is related to establishing information, a method devised in this study will make a great contribution to developing relevant industry.

\section{Acknowledgments}

This research was supported by Basic Science Research Program through the National Research Foundation of Korea(NRF) funded by the Ministry of Science and ICT(No. NRF-2018R1C1B6004021).

\section{References}

[1] M. K. Chung, C. J. Kim, K. H. Choi D. K. Chung, and Y. I. Kim, "Development of LiDAR Simulator for Backpack-mounted Mobile Indoor Mapping System", Journal of the Korean Society of Surveying, Geodesy, Photogrammetry, and Cartography, vol. 35, no. 2, (2017), pp. 91-102.

[2] D. G. Lee and D. C. Lee, "Key Point Extraction from LiDAR Data for 3D Modeling", Journal of the Korean Society of Surveying, Geodesy, Photogrammetry and Cartography, vol. 34, no. 5, (2016), pp. 479-493, 2016.

[3] J. K. Park and K. Y. Jung, "Investigation and Analysis of Forest Geospatial Information Using Drone", Journal of the Korea Academia-Industrial Cooperation Society, vol. 19, no. 2, (2018), pp. 602-607.

[4] N. Wang, P. Jin, Y. Xiong and L. Yue, "A Multi-Granularity Grid-Based Graph Model for Indoor Space", International Journal of Multimedia and Ubiquitous Engineering, vol. 9, no. 4, (2014), pp. 157170.

[5] J. K. Park and K. W. Lee, “Analysis of Geospatial Information Construction Efficiency by 3D Laser Scanner Integrated with Total Station", Journal of the Korea Academia-Industrial Cooperation Society, vol. 18, no. 12, (2017), pp. 638-643.

[6] J. G. Yim, J. H. Joo and G. Y. Lee, "Petri Net-Based Ontology Analysis Method for Indoor LocationBased Service System", International Journal of Advanced Science and Technology, vol. 39, no. 1, (2012), pp. 75-92.

[7] G. S. Lee, I. H. Jeong, Y. S. Choi and S. B. Kim, "A Fundamental Study about a Quality Certification of 3D Precision Indoor Geospatial Information - Focused on Yeongdeungpo Station -", Journal of the Korean Society for Geospatial Information Science, vol. 23, no. 1, (2015), pp. 3-14.

[8] M. S. Rahman and K. D. Kim, "Indoor Location Estimation Using Visible Light Communication and Image Sensors", International Journal of Smart Home, vol. 7, no. 1, (2013), pp. 99-114.

[9] J. H. Park, S. H. Kang, S. H. Kim and W. H. Lee, "A Study of Estimation of AP Position for Improvement of Indoor Positioning Performances", International Journal of Control and Automation, vol. 5, no. 2, (2012), pp. 73-80.

[10] D. Roca, J. Armesto, S. Lagüela and L. Díaz-Vilariño, "LiDAR-equipped UAV for Building Information Modeling", The International Archives of the Photogrammetry, Remote Sensing and Spatial Information Sciences, vol. XL-5, (2014), pp. 523-527.

[11] J. Wang and D. Katabi, "Dude, where's my card: RFID positioning that works with multipath and nonline of sight”, ACM SIGCOMM Computer Communication Review, vol. 43, no. 4, (2013), pp. 51-62. 
[12] T. Van Haute, E. De Poorter, F. Lemic, V. Handziski, N. Wirstrom, T. Voigt, A. Wolisz and I. Moerman, "Platform for benchmarking of RF-based indoor localization solutions", IEEE Communications Magazine, vol. 53, no. 9, (2015), pp. 126-133.

[13] C. H. Kim, H. W. Kim, G. M. Kang, G. Y. W. H. Kim, C. H. Park, J. D. Do, M. H. Lee, S. Y. Choi and H. Y. Park, "Shipborne Mobile LiDAR(Light Detection and Ranging) System for the Monitoring of Coastal Changes", Economic and environmental geology, vol. 49, no. 4, (2016), pp. 281-290.

[14] D. Lague, N. Brodu and J. Leroux, "Accurate 3D comparison of complex topography with terrestrial laser scanner: application to the Rangitikei canyon (NZ)", ISPRS Journal of Photogrammetry and Remote Sensing, vol. 82, (2013), pp. 10-26.

[15] K. Q. Zhang, S. C. Chen, D. Whitman, M. L. Shyu, J. H. Yan and C. C. Zhang, "A progressive morphological filter for removing nonground measurements from airborne LiDAR data", IEEE Trans. Geosci. Remote Sens., vol. 41, no. 4, (2003), pp. 872-882.

[16] H. S. Moon and W. S. Lee, "Development and Verification of a Module for Positioning Buried Persons in Collapsed Area", Journal of the Korea Academia-Industrial Cooperation Society, vol. 17, no. 12, (2016), pp. 427-436.

[17] G. S. Sim, "Metadata Design Based on Vector Type Geospatial Information Standard for the Collection and Management of Inundation Map", Journal of the Korea Academia-Industrial Cooperation Society, vol. 17, no. 5, (2016), pp. 42-48.

[18] J. K. Park and E. S. Lee, "Applicability Estimation of Mobile Mapping System for Eefficient Construction of Road Geospatial Information", Journal of the Korean Association of Cadastre Information, vol. 16, no. 2, (2014), pp.185-192.

[19] S. P. Choi, J. H. Ham, M. S. Kim, I. T. Yang and U. N. Kim, "Slope Terrain Analysis According to Geographical Feature and Survey Place Based on Terrestrial LiDAR Data", Journal of the Korean Society for Geospatial Information System, vol. 8, no. 2, (2010), pp. 63-68.

[20] J. E. Kim and S. C. Hong, "(A) study on location correction method of indoor/outdoor 3D modelthrough data integration of BIM and GIS", Journal of the Korea Academia-Industrial Cooperation Society, vol. 18, no. 3, (2017), pp. 56-62.

[21] S. Y. Won, S. W. Lee, J. C. Paik, C. Y. Yune and G. H. Kim, "Analysis of Erosion in Debris Flow Experiment Using Terrestrial LiDAR", Journal of the Korean Society of Surveying, Geodesy, Photogrammetry and Cartography, vol. 34, no. 3, (2016), pp. 309-317.

[22] Y. S. Jwa, G. H. Sohn, J. U. Won, W. C. Lee and N. H. Song, "Railway Track Extraction from Mobile Laser Scanning Data", Journal of the Korean Society of Surveying, Geodesy, Photogrammetry and Cartography, vol. 33, no. 2, (2015), pp. 111-122.

[23] Trimble Navigation Ltd.,(2018), http://www.trimble.com.

\section{Authors}

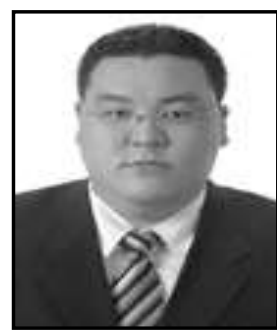

Joon-Kyu Park is currently a Professor in Department of Civil Engineering at Seoil University. He received his B.S., M.S. and Ph.D. degree in Civil Engineering from Chungnam National University in 2001, 2003, 2008, respectively. His research interests are in the areas of GPS, Geo-Spatial Information Engineering.

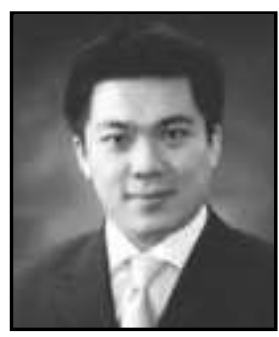

Kap-Yong Jung, he received his B.S., M.S. and Ph.D. degree in Civil Engineering from Chungnam National University in 2003, 2009, 2013, respectively. His research interests are in the areas of Geodetic Science, Surveying, Geospatial Information. 
International Journal of Control and Automation

Vol. 11, No. 9 (2018) 